\title{
Relationship between health literacy and health promoting behavior in patients with heart failure referred to clinics of Shahid Beheshti University of Medical Sciences
}

\author{
Mahrokh Imanian', Meimanat Hosseini ${ }^{2 *}$, Tahereh Ashk Torab ${ }^{3}$, Nezhat Shakeri ${ }^{4}$ and \\ Mahsa Matbouei ${ }^{5}$ \\ ${ }^{1}$ Department of Medical Surgical Nursing, Student's Research Office, Shahid Beheshti University of Medical \\ Sciences, Tehran, Iran \\ ${ }^{2} P h D$ in Nursing, Assistant Professor of Community Health Nursing Department, School of Nursing and \\ Midwifery, Shahid Beheshti University of Medical Sciences, Tehran, Iran \\ ${ }^{3}$ PhD in Nursing, Assistant Professor of Nursing Department, School of Nursing and Midwifery, Shahid \\ Beheshti University of Medical Sciences, Tehran, Iran \\ ${ }^{4} \mathrm{PhD}$ in Biostatistics, Department of Biostatistics, Faculty of Paramedical Sciences, Shahid Beheshti \\ University of Medical Sciences, Tehran, Iran \\ ${ }^{5}$ Instructor of Nursing (MSc), Dept.of Community Health Nursing, School of Nursing \& Midwifery Shahid \\ Beheshti University of Medical Sciences, Tehran, Iran
}

\begin{abstract}
Patients with heart failure are considered one of the most important groups exposed to the danger of low health literacy that may affect their health-promotion behaviors and quality of life and increase the load of health-related costs. Therefore, the present study aimed to determine the relationship between health literacy and health-promoting behaviors in patients with heart failurewho referred to heart clinics of Shahid Beheshti University of Medical Sciences.This correlational study was conducted on 300 heart failure patients, selected byrandom cluster sampling method with proportional allocation. Data collection tool was demographic information questionnaire,Health literacy measurement and Health promoting Lifestyle Profile 2 (HPLP2). Data analysis was performed using SPSS software version 19 though statistical tests, includingindependent t-test, Pearson and Spearman correlation coefficient, Mann-
\end{abstract}

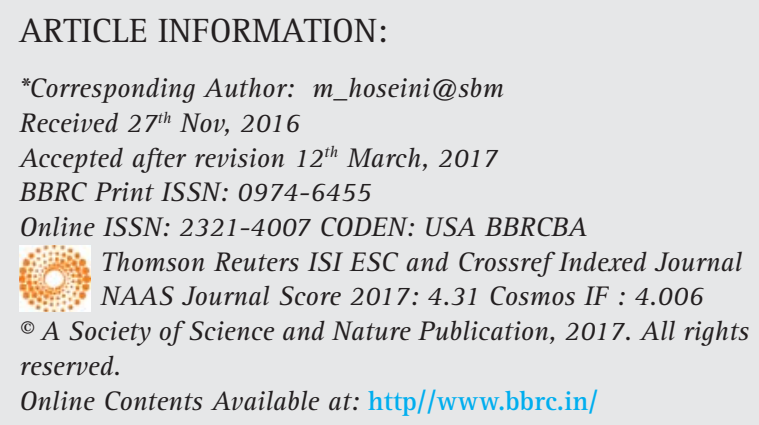


Whitney-U test and Kruskal-Wallis. The results showed that mean and standard deviation (SD) score ofhealth literacy of participants was $3.29 \pm 0.6$ and meanand SD score of health-promoting behaviors was $2.42 \pm 0.29$. The Pearson correlation coefficientshoweddirect and significant relationship between health literacy andhealth-promoting behaviors $(\mathrm{r}=0.66, \mathrm{P}<0.001)$. The results of this research showed the statistically significant relationship between health literacy level and health-promoting behavior. Therefore, health literacy should be paid special attention, as a factor affectinghealth-promoting behaviors, healthy life style and quality of life. According to the results of this study, programmingeducation and development of health-promoting behaviorsin patients with heart failure suggest that the health literacy needsmore attention inhealth-promotion plans.

\section{KEY WORDS: HEALTH LITERACY, HEALTH-PROMOTING BEHAVIOR, PATIENT, HEART FAILURE}

\section{INTRODUCTION}

The prevalence ofchronic diseases is a challenge in the present century in health and treatment sector (Karbaschi et al. 2012). Among chronic diseases, the prevalence of congestive heart failure is increasing(Rahnavard et al, 2006). As in the whole world, 23 million people are suffering fromheart failure and annually two million new casesof heart failureare diagnosed(Shiba and Shimokawa, 2011). However, inIran,no detailed data exists from people withheart failure(Rezaee loye et al, 2009). At the same time, with increase in number of patients suffering from chronic diseases, likeheart failure, systems presenting health services face numerous difficulties in long runtoprovide services to these people. In other words, chronic diseases need chronic care. Therefore, many believe that self-care should be performed by patients, in order toorganize these patients and facilitate their affairs(Mellen, 2002). Based on the findings of previous studies, high mortality rate, inappropriate use of preventive services, and deterioration ofheart failureare associated with inadequate health literacy (Dennison et al, 2011).

Inadequate health literacy is defined asthe limited ability of people for acquiring, interpreting, and understanding primary information and health services that are necessary for appropriate decision-making inhealth areas (Raisi et al, 2013). Among patients with heart failure, as well,low health literacy is associated with mortality (Eckman et al, 2015).

According to studies by American Center for Health Care Strategies,people withlow health literacy are unlikely tounderstand and practice the written and oralinformation presented by the specialists(Raisi et al, 2011). Recent reviews have reported poor health literacy in 33 to $51 \%$ of adults discharged from hospitals and more than60\% of referrals to cardiac clinics (Fernandez, 2014); while,heart failuredisease can affect routine life activities, due to its natural capability. As a result, these patients become dependent to others for selfcare (Abbasi et al, 2010). Today, health literacy is also an important concept inwidespread aspects of health promotion (Kanj and Mitic, 2010).Epidemiologicalstudies have shown that the development of risk factors for coronary artery disease can be controlled by having a healthy lifestyle and people can improve their health through health-promoting behaviors (Mohseni Pouya et al, 2016).

Pender have suggestedthat health-promoting behaviors including exercise, nutrition, stress management, interpersonal relationship, spiritual growth, and health responsibilities reduce the risk of disease (Hosseini et al, 2015). These behaviorsare one of themajor measures exterminating health that is known as abackground factor in preventing many diseases (Raisi et al, 2011). With regard to the importance of two issues ofhealth literacy and health-promoting behaviorsin patients with heart failure and regarding the report ofAgency for Health Care Research and Quality on need for further researches more on health literacy and the way itaffects people's health (Raisi et al., 2013) and consideringthe fact that until now the relationship between health literacy andhealthy behaviorsin cardiac patients has not been studied inIran, the present research evaluated the relationship between health literacy level and healthpromoting behaviorsin patients with heart failure as one of the most important vulnerable groups.

\section{MATERIALS AND METHODS}

Inthis correlational study, a total of 300 of patients suffering from heart failure referred to cardiac clinics of hospitals affiliated to Shahid Beheshti University of Medical Sciences were selected by random cluster sampling according to the following inclusion criteria: diagnosis of heart failure grade 2 and 3 in medical records according to doctor's diagnosis, minimum age of 25 years and maximum of 65 years, ability to read and write Farsi texts, passing at least six monthsafter finaldiagnosis of the disease, receivingpharmaceutical treatment for heart failure (pills and medicinal regimen). Datawas collected through two questionnaires and a scale that included the following tools: 
1. Demographic information questionnaire (including a total of 7 questions, 5 questions related to personal information and 2 questions related to the disease).

2. Health literacy measurement: This tool was designed by Montazeri et al.,in 2014that includes 33 items in 5 domains; 4 of theminclude access, understanding, assessment, decision-making, and employing the information, each containing 6, 7, 4 , and 12 items, respectively, and the reading skill contains 4 items with 5-item Likert scale.

3. HPLP2: This scale is used toassesshealth-promoting behavior, which includes spiritual growth, responsibility, physical activity, nutrition, interpersonal relationship, and stress management, designed by Walker et al (1987), containing 52 items and 4-optionLikert scale that wastranslated by Hosseini et al., in 2010 (Hosseini, 2013).

In the present research, validity of the demographic questionnaire was determined through qualitativemethod. Also, todetermine the validity, other qualitative method was used to determinefacevalidity and qualitative and quantitative methods were used for determine content validity. Content validity index (CVI)was determined using quantitative methods. For this purpose, opinion of 10 experts in thenursing field was used. CVI of the Health literacy measurement and HPLP2 was 0.92 , and 0.94 , respectively. To determine the reliability of the tools in the present study, internalconsistency (Cronbach's alpha) and stability (Interclass Correlation Coefficient (ICC)) were used. Cronbach's alpha coefficient of the total health literacy tool and HPLP2 was $\alpha=0.78$, and 0.87 , respectively. Also, total ICC of this tools was calculated $\alpha=0.82$, and 0.79 , respectively. To gather data, afterconfirming the proposal of the research and getting introduction letter and receivingsampling license, 7 hospitals were purposively selected based on the list of hospitals with cardiac clinic affiliated toShahid Beheshti University of Medical Sciences, Tehran. Then, one of the researchersselected hospitals randomly and referred to each clinic (which was assessed by the researcher before) during working hours. Then, samples were selected randomly among patients with qualified conditions of sampling in the research. Then, while providing necessary explanation about the research objectives and emphasis on confidentiality of data, written informed consent letter was obtained from patients and the research tools were completed orally and by asking participants.

To analyze data, SPSS software version 19 was used. To report descriptive data,mean and SD, frequencyand percentage were used. To analyze data in inferential statistics, Kolmogorov-Smirnov test was used and when the data distribution was normal,parametric tests(independent t-test, Pearson correlation coefficient) and when the data distribution was not normal, nonparametric tests (Mann-Whitney-U, Kruskal-Wallis and Spearman correlation coefficient) were used. Finally, after univariate analysis, to assess the impact of variables beside each other on the outcome variable (health promotion behaviors), all variables witha possibility greater than 0.2 enteredmultiple regression model.

\section{RESULTS AND DISCUSSION}

The results showed that men included 51.7\% of patients with heart failure and 86\% were married. Mean and SDof age of participants was $54.83 \pm 8.21$ and they were mostly at age range 60 to 65 years. $39.3 \%$ of participants had secondary school education and 98\%had no history of employment inarea of medical sciences. Most of participants (57.7\%) had a monthly income of less than 250,000 Tomans per family member. Also, 90\% of participants stated a history of hospitalization due to heart reasons. At the same time, $84 \%$ of the participants claimed no history of education in the form of leaflets, pamphlets or oral training (Table 1).

Based on the results of the current study,mean and SD score of health literacy in patients with heart failure was $3.29 \pm 0.6$ and $87.7 \%$ of participant showed moderatehealth literacy. Also, mean and SD of health-promoting behaviors of participant in the study was $2.42 \pm 0.29$ and 57\% of participant had moderate level. Resultsof Pearson statistical test showeda significant positive correlation betweenhealth literacy and health-promoting behaviors $(\mathrm{P}<0.001)$. Therefore, higher level of health literacy increased the health-promoting behaviors score in patients with heart failure.

Amongthe subscales of health literacy,mean and SD scores of total participants in thereading skill was higher than other skills $(3.8 \pm 0.87)$, and in the aspect of evaluation and decision-making,the mean and SD scores of people was less than other factors $(3 \pm 0.83)$. The results of independent t-test showed no significant difference in scores of overall health literacy between women and men $(\mathrm{P}>0.05)$. Among other demographic variables of health literacy, marital status and monthly income had a significant relationship $(\mathrm{P}>0.05)$. Pearson correlation test showed significantdifference intotal health literacy at different age groups with education $(\mathrm{P}<0.001)$. Table 2 shows the correlation of health literacy with age and educational status of participants in the research.

Inthe fields of health-promoting behaviors, mean and SD scores of participantswas higher in interpersonal relationship thanother subscales $(2.8 \pm 0.34)$ and was the leastin the stress management with a mean and SD of 
Table 1. Frequency of distribution of demographic characteristics of patients

\begin{tabular}{|c|c|c|c|}
\hline \multicolumn{2}{|l|}{ variable } & number & $\%$ \\
\hline \multirow{2}{*}{ Sex } & male & 155 & 51.7 \\
\hline & female & 144 & 48.3 \\
\hline \multirow{4}{*}{ Education } & primary & 81 & 27 \\
\hline & Middle (guidance level) & 118 & 39.3 \\
\hline & Secondary & 14 & 4.7 \\
\hline & College & 43 & 43 \\
\hline \multirow{2}{*}{ Employment status } & Working in medical sciences & 4 & 1.3 \\
\hline & Not employed in medical sciences & 296 & 98.7 \\
\hline \multirow{4}{*}{ Marital status } & Single & 15 & 5 \\
\hline & Married & 258 & 86 \\
\hline & Divorced & 1 & 0.3 \\
\hline & Widow(er) & 26 & 8.7 \\
\hline \multirow{8}{*}{ Age } & $25-29$ & 4 & 1.3 \\
\hline & $30-34$ & 5 & 1.7 \\
\hline & $35-39$ & 6 & 2 \\
\hline & $40-44$ & 20 & 6.7 \\
\hline & $45-49$ & 20 & 6.7 \\
\hline & $50-54$ & 75 & 25 \\
\hline & $55-59$ & 51 & 17 \\
\hline & $60-65$ & 119 & 39.7 \\
\hline \multirow{2}{*}{ Monthlyincome } & Morethan 250,000 Tomans per family member & 32 & 32 \\
\hline & Lessthan 250,000 Tomans per family member & 36 & 36 \\
\hline \multirow{2}{*}{ History of hospitalization } & Yes & 270 & 90 \\
\hline & No & 30 & 10 \\
\hline \multirow{2}{*}{ Historyof education } & Yes & 48 & 16 \\
\hline & No & 252 & 84 \\
\hline
\end{tabular}

$2.21 \pm 0.32$, had the lowest score. The results of independent t-test showed significant differences in health-promoting behaviors betweenthe studied women and men $(\mathrm{P}=0.02)$ andstudied men were in better condition. Total health-promoting behaviorswere significantly associated only with monthly income $(\mathrm{P}<0.001)$. Pearson correlation coefficient showed significant differences in health-promoting behaviors in different age groups and educational status $(\mathrm{P}<0.001)$. The correlation test of health-promoting behaviors with education level and

Table 2. correlation between health literacy and healthpromoting behavior with age and educational level

\begin{tabular}{|l|l|l|l|l|}
\hline \multirow{2}{*}{ Scale } & \multicolumn{2}{|c|}{ Age } & \multicolumn{2}{c|}{ Educationalstatus } \\
\cline { 2 - 5 } & $\mathrm{r}$ & $\mathrm{p}$-value & $\mathrm{r}$ & $\mathrm{p}$-value \\
\hline Health literacy ${ }^{* * *}$ & -0.41 & $<0.001$ & 0.82 & $<0.001$ \\
\hline $\begin{array}{l}\text { Health-promoting } \\
\text { behavior*** }\end{array}$ & -0.18 & 0.002 & 0.6 & $<0.001$ \\
\hline
\end{tabular}

age are expressed in table 2. Also, table 3 shows the correlation between health literacy and health-promoting behaviors subscales in the study subjects.

\begin{tabular}{|l|l|l|}
\hline \multicolumn{3}{|l|}{$\begin{array}{l}\text { Table 3. Correlation between health literacy and } \\
\text { subscales of health-promoting behaviorsin study } \\
\text { subjects }\end{array}$} \\
\hline $\begin{array}{l}\text { Subscale of health-promoting } \\
\text { behaviors }\end{array}$ & \multicolumn{2}{|c|}{ Health literacy } \\
\cline { 2 - 3 } & r & p-value \\
\hline Nutrition** & 0.516 & $<0.001$ \\
\hline Physical activity ** & 0.520 & $<0.001$ \\
\hline Interpersonal relationship *** & 0.457 & $<0.001$ \\
\hline Health responsibility** & 0.547 & $<0.001$ \\
\hline Spiritual growth** & 0.607 & $<0.001$ \\
\hline Stress management*** & 0.544 & $<0.001$ \\
\hline Total health-promotingbehavior & 0.66 & $<0.001$ \\
\hline${ }^{* *}$ Correlation is significant at 0.05. & & \\
\hline
\end{tabular}


Table 4. The results of multiple regression model fitto assess effective factors on health-promoting behaviors

\begin{tabular}{|l|l|l|l|l|}
\hline Variable & $\begin{array}{l}\text { Non-standardized } \\
\text { regression coefficients }\end{array}$ & $\begin{array}{l}\text { Standard deviation of } \\
\text { regression coefficients }\end{array}$ & $\begin{array}{l}\text { Standardized } \\
\text { regression coefficients }\end{array}$ & $\mathrm{p}$-value \\
\hline Intercept & 0.53 & 0.24 & & 0.03 \\
\hline Health literacy & 0.29 & 0.03 & 0.59 & $<0.001$ \\
\hline Secondary school education & -0.15 & 0.07 & -0.26 & 0.03 \\
\hline Age & 0.005 & 0.002 & 0.1 & 0.005 \\
\hline Income status & 0.1 & $029 / 0$ & 0.17 & $<0.001$ \\
\hline
\end{tabular}

The results of multiple regression models showed that health literacy, education, age and income status were effective factors onhealth-promoting behaviors $(\mathrm{P}>0.05)$. Health-promoting behaviors in people with secondary schooleducation had a0.13 less mean value than people with college education and each unit increase in age, increasedmeanHealth-promoting behaviors at 0.005 units.Health-promoting behaviors in people with an income more than 250,000 Tomans per person had a mean 0.1 unit increased than people with income less than 250,000 Tomans per person. Each unit increase inhealth literacy increased the meanHealth-promoting behaviors0.29 units. Among theabove-mentioned variables, health literacy had the greatest impact on health-promoting behavior. The results ofmultiple regression models are demonstrated in table 4 .

\section{DISCUSSION}

The results showed that more than two-thirds of heart failure patients have moderate health literacy. This finding is consistent with the results of studies byTehraniBanihashemiet al., 2007; Raisi et al., 2013; Mollakhalili et al., 2014; Mo'tamedi et al., 2016; Raisi et al., 2011 inside our country, and abroad researchesby Tung et al., 2014; Moseret al., 2015; and Jovis_veranes et al., 2011. Regarding the findings of the above-mentioned studies, it should be noted that patients withchronic conditions, like heart failureare at greater risk ofinadequate care and weak consequences, such as lack of knowledge ofdisease, poor care, increasednumber of hospitalization and mortality caused by the disease.So, patients need adequate health literacy to participate in health care systems and appropriate health decisions (Mollakhalili et al., 2014).

Theresults of the current study showed that health literacy is an important factor affecting health-promoting behaviors in heart failure patients. Tsai et al (2014) and Raisi et al (2013) also found similar results in their study. In the present study, patients with higher health literacy had a better condition in all aspects of health promoting behaviors. As increase in patients'health literacy increased the physical activity levels. Also, these people had a better nutritional status and sense of responsibility to their health. In this regard,Mollakhalili et al (2014) have pointed out that health literacy led to empowerment of people to apply information and health-related commands. Considering the effect of health-promoting behaviorsin patients with heart failure on advancing health and quality of life, it decrease health-related costs to the same proportion, so health literacy should be consideredas a factor that promotes healthbehaviors, create healthy life style and finally improves the quality of life. Meanwhile, the weaker health literacy was more prevalent among older patients. Higherhealth literacy in younger patients can be attributed to the fact that inthe present study,this group with higher level education and more information on application of communicational media, like internet, has fewer problems and higher mean scores compared to older patients. Also, the higher physical power and probably lower incidence of comorbidities of heart failure, such as diabetes and hypertension,and lessinvolvement of the joints cause higher physical activity were observed in younger patients. Based on the findings of the present research, health literacy had no significant relationship with gender of patients $(\mathrm{P}>0.05)$. Therefore, the amount and method of understanding and interpretation of health information were not different betweenwomen and men and both groups need attention of the authorities concerned in this regard. But independent t-test showed significant difference between gender andhealth-promoting life style $(\mathrm{P}<0.05)$. According to the results of the current study, generally, men were more likely to take care of their health than women. In the study by Tallet al (2014) and Nuthwer and Stump (2000), there was also a significant relationship betweenhealth-promoting life style and sex $(\mathrm{P}<0.001)$. In the present study, all sub-scales ofhealth literacy and health-promoting behaviorshad higher scores among college-educated individuals than those with lower educational level. Tsai's study (2014), as well,showed a significant association between education and health literacy and these people were more likely to have aneducational level above high school $(\mathrm{P}<0.001)$. Notably,in thepresent study, allparticipants were literate, who were placed in that 4 educational groupsandhigher 
level of education will possibly improve theirhealth literacy. But in other studies in this regard, people's educational levelwere categorized as literate and illiterate that could have animpact on the results of the study.

Lev and Owen (2000) writesin this regard that knowledge and education increases thepotential ability of the person against confusion and tension-causing factors and cause success in self-care behavior. As academic history of people is directly and meaningfully associated with health literacy,it is necessary to pay more attention to education and societyhealth literacy, especially on health information. Developing appropriate health programs, providingsimple and understandable training materials, spendingmore time with patients andslower interviews by doctors and medical staff are the solutions to help patients with lowhealth literacy to improve theirliteracy. Inthe present study, the difference between people with and without a history of work experience in medical areaswas not significant inhealth literacy $(\mathrm{P}=0.3)$ and health-promoting behaviors $(\mathrm{P}=0.9)$. This lack of difference is probably due to the small number of people employed in medical sciencesparticipating in the present study that accounted for only 1.3\% of them. Regarding the fact that the majority of participants in the present study had secondary school education, lack of high level health and treatment activity seems logical at this level of education. Another result of the present study indicated that except interpersonal relationship $(\mathrm{P}=0.13)$ and health responsibility $(\mathrm{P}=0.9)$, other dimensions ofhealth-promoting behaviorshad a significant relationship with income status $(\mathrm{P}<0.05)$, which can guide us to the fact that higher income does not necessarily lead to higherhealth responsibility and vice versa, people fromlow level of society do not take less care of their health; thus, training programs should be performed for all classesof the society. But higher mean scores of people inother dimensions, like nutrition, was due to higher income and can be justified due to better access to nutrition.

Inthe present study, the mean score of total health literacy and health-promoting behaviors was higher in trained people than untrained, but this difference was only significant in health literacy $(\mathrm{P}<0.001)$. Health literacy $(\mathrm{P}=0.2)$ and health-promoting behaviors $(\mathrm{P}=0.6)$ had no significant relationship with history of hospitalization, so that people withno history of hospitalization had highermean scores in both variables. It seems that when the patient has no history of hospitalization after 6 months from definite diagnosis of heart failure, it confirmshigher health literacy and more adherences tohealth-promoting behaviorsin the patient. Thus, the results of this research emphasize the importance of health literacy in the society, especially in hospitalized patients.

\section{STUDY LIMITATIONS}

In general, in this study, high number of questions of the tools used was one of the limitations, which was tried to be confronted by the following measurements: dedicateenough time to samples,answer their questions, consider a short break during interviews, and change the order of the research tools to be completed. In addition, the present study was performed in a cross-sectional basis, so future research with longer follow-ups can providea better understanding of the causality relationships between variables.

\section{CONCLUSION}

The results of the current research showed that most of patients had moderate (borderline)health literacy. Therefore, these patients require more explanations by medical staff to understand and implement thedoctors' instruction and other information and it is necessary to provide more time for relationships with their physicians and nurse and receivea simpler and more understandable information. Also, health managers and caregivers should pay attention to this issue and spend more time and give health instructions to this category ofpatients. In the end, assessinghealth-promoting behaviorsand understanding the factors affecting it is of great importance that could improve the quality of life of patients with heart failure, but it needs policy-making and planning in this area. Theimportance of health-promoting behaviorsshould be considered more than before and be included inhealth care policy-making and programs. Regarding the vulnerability of heart failure patients and increasing prevalence in near future and the resulting associated challenge, planning is essential to face this challenge and lack of programing and policy-making in this regard will cause serious social, economic and health problems for society.

\section{ACKNOWLEDGEMENTS}

The present article is the result of master's thesis and research project with the Ethics code sbmu2.rec.1394.138 in Shahid Beheshti School of nursing and midwifery. The researchers express their sincere thanks to all who helped us in different phases of the study, the respected officials of Shahid Beheshti School of nursing and midwifery, patients with heart failure, managers of heart 
clinics in teaching hospitals affiliated to Shahid BeheshtiUniversity of Medical Sciences.

\section{REFERENCES}

Abbasi A, Asayesh H, Hosseini S.A, Ghorbani M, Abdullahi A.A, Rouhi Gh, Rahmani H. (2010) The relationship between function and quality of life in patients with heart failure. South medical journal. 13(1) 31-40.

Dennison CH, Mcentee M, Samuel L, Johnson B, Rotman S, Kielty A, Russell S.D (2011) Adequate health literacy is associated with higher heart failure knowledge and self-care confidence in hospitalized patients. J Cardiovasc Nurs. 26(5): 359-367.

D (2014) Health literacy and related psychosocial factor and measurement issues: A qualitative study and secondary analysis of the health and retirement study. Dissertation Submitted in Partial Fulfillment of The Requirement For The Degree of Doctor of Philosophy (Nursing). University of Michigan.

of nursing in Universities of Tehran, behaviorspattern test. Doctoral thesis for nursing. Shahid Beheshti University of Medical Sciences.

promoting behaviors and their association with certain demographic characteristics of nursing students of tehran city in 2013. Global Journal of Health Science; 7(2).

Hosseini M, Ashktorab T, Taghdisi M.H, Esmaeili Vardanjani A, Rafiei H (2015) Health-promoting behaviors and their association with certain demographic characteristics of nursing students of tehran city in 2013. Global Journal of Health Science; $7(2)$.

Hossein Mohsenipouya, Fereshteh Majlessi, Davood Shojaeizadeh, Abbas Rahimi Foroushani, Rahman Ghafari, Vali Habibi, and Azam Seyfi Makrani (2016) Health-related variables and predictors of Health-promoting Lifestyle in cardiovascular disease patients. Electron Physician. 2016 Apr; 8(4): 2274-2280.

population of primary healthcare patients in belgrade, serbia. Int J Public Health. 56(2):201-207.

Kanj m, mitic w (2010) Health literacy and health promotion, definition, concepts and examples in estern mediteranian region. Who Regional Office fot the Estern Mediteranion.

Karbaschi K, Farsi S.A. (2012) Revealing the concept of selfcare and its application for nurses. Journal of nursing Military School of Republic of Islamic Iran. 12(1). 22. 14-16.

Mollakhalili H, Papi A, Sharifirad Gh.R, Zare-Farashbandi F, Hasanzadeh A (2014) Health literacy in patients hospitalized at educational hospitals affiliated to Isfahan University of Medical Sciences. Health information management. 11(4). 364-373.

Nothwehr F,Stump T (2000) Health-promoting behaviors among adults with Type 2 Diabetes. Findings from the Health and Retirement Study. Preventive Medicine. 30. 407-414.
Lev E.L, Owen S.V (2000), Counseling women with breast cancer using principles developed by albert bandura. Perspective in psychiatric Care; 36(4):131-139.

McNaughton C.D, Cawthon C, Kripalani S, Liu D, Storrow A.B, Roumie CH.L (2015) Health literacy and mortality: A cohort study of patients hospitalized for acute heart failure. American Health Association (J Am Heart Assoc).

Mellen P.B (2008) Deteriorating dietary habits among adults with hypertention. Archives of Internal Medicine. 168(3). 308314.

Moser D.K, Robinson S, Biddle M.J, Pelter M.M, Nesbitt T.S, Suthard J, Cooper L, Drucup K (2015). Health literacy predicts morbidity and mortality in rural patients with heart failure. Journal of Cardiac Failure. 21(8).

Motamedi F, Malekzadeh S, Azami M, Mirzaei M (2016) Health literacy of cardiovascular patients admitted to private hospitals in Kerman. International Journal of Advanced Biotechnology and Research (IJBR). 7(1). 239-247.

Rahnavard Z, Zolfaghari M, Kazemnejad A, Hatamipour Kh. (2006) Assessing the quality of life and factors affecting it in patients with congestive heart failure. Journal of School of nursing and midwifery of Tehran University (Hayat). 12(1) 77-86.

Rezai-Loye H.A, Dalvandi A, Hosseini M.A, Rahgozar M. (2008) The effect of self-care education on quality of life in patients with failure of heart. Rehabilitation. 2(10).38

Raisi M, Javadzadeh S.H, Mostafavi F, Tavasoli A, Sharifirad Gh.R (2013) Health literacy and health-promoting behaviorsin elderly of Isfahan. Journal of health system research. 8(9). 127-836.

Raisi M. Mostafavi F, Hasanzadeh A, Sharifırad Gh. (2011) The relationship betweenhealth literacy andgeneral health status healthbehaviorsin elderly city of Isfahan. Journal of health system research. 7(14).

Shiba N, Shimokawa H (2011) Prospective care of heart failure in Japan: lessons from CHART studies. European Association for Predictive, Preventive and Personalised Medicine(EPMA Journal). 2: 425-438.

Tsai M.H, Cheng Ch.Y, Chang Sh.Ch, Yang Y.M, Wang H.H (2014) Health literacy and health promoting behaviors among multiethnic groups of women in Taiwan. JOGNN. 43. 117-129.

Tol A, Mohebbi B, Sadeghi R,V Maheri A,B, Eshraghian M.R (2014) Determinants of Health-Promoting Behaviors among Type 2 Diabetic Patients: Voice of Iran. Journal of Endocrine and Metabolic Diseases. 4. 219-224.

Tung H.H, Lu T.M, Chen L.K, Liang Sh.Y Shu-Fang Wu Sh.F, Chu K.H (2014) Health literacy impact on elderly patients with heart failure in Taiwan. Journal of Clinical Gerontology \& Geriatrics. 5. 72-76. 